\title{
Symmetric and asymmetric analysis of tourist behavioral intention's antecedents
}

\author{
Beykan Çizel ${ }^{1}$ (D) I İsmail Gökay Kırtıl ${ }^{2}$ (D) . Volkan Aşkun² (D) Edina Ajanovic ${ }^{3}$ (D) . \\ Hatice Karakaş ${ }^{1}$ i
}

Accepted: 12 November 2021 / Published online: 7 February 2022

(c) The Author(s), under exclusive licence to Springer Nature B.V. 2022

\begin{abstract}
This paper aims to test the effect of structural relations between memorable tourism experience, destination brand personality, destination place attachment and tourist satisfaction on tourist behavioral intention within a theoretical model. Two different methods were applied for research purposes. First, structural equation modeling was used to analyze linear effects and relationships. Afterwards, as part of asymmetric analysis, fsQCA was used to reveal sufficient and necessary configurations to predict tourist behavioral intention. The results indicate that tourists' future intentions can be predicted by both symmetric and asymmetric models. Linear analysis demonstrated that memorable tourism experience has positive effects on brand personality, attachment, satisfaction and consequently on intention of tourists. Thereafter, asymmetric analysis revealed that satisfaction was necessary for intention, whereas memorable tourism experience, attachment and brand personality were sufficient for intention. While fsQCA provides a supplementary perspective to the structural model, results indicate mediating relationships and configurational variations of research variables.
\end{abstract}

Keywords Memorable tourism experience $\cdot \mathrm{fsQCA} \cdot$ Destination brand personality $\cdot$ Place attachment $\cdot$ Satisfaction $\cdot$ Behavioral intention

Beykan Çizel

beykan@akdeniz.edu.tr

$\triangle$ Hatice Karakaş

haticekarakas@akdeniz.edu.tr

İsmail Gökay Kırtıl

gokay@akdeniz.edu.tr

Volkan Aşkun

volkanaskun@gmail.com

Edina Ajanovic

eajanovic@outlook.com

1 Tourism Faculty, Akdeniz University, Dumlupinar Boulevard, 07070 Antalya, Turkey

2 Demre Dr. Hasan Ünal Vocational School, Akdeniz University, 07570 Demre, Antalya, Turkey

3 Talya Software, Technocity, Akdeniz University, Dumlupinar Boulevard, 07070 Antalya, Turkey 


\section{Introduction}

While travelling and staying at a destination, tourists temporarily escape from their regular environment, suspending their thoughts about own lives and power of daily life's values and norms, and meeting their psychological needs with feelings such as pleasure, exploration, personal development, socialization and relaxation. In his phenomenological study, Cohen (1979) defines the tourism experience as the relationship between people and the worldview of the society in which they belong to, while Urry (1990) describes it as a movement or activity that provides opportunity for a different perspective on life or to escape from monotony. Tourism researchers have suggested tourism experiences as extraordinary events that stand out in a more distinguishable way than ordinary ones (Cohen 1979; MacCannell 1973). In order to summarize the evolution of tourism experience concept into memorable one, Csikszentmihalyi's (1975) study can be considered as one of the first that emphasized satisfaction as the main result of this experience.

As tourism experience gained importance, Kim (2018) underlined that it should be put at the center of service provision. This view challenged the logic of meeting the expectations of customers by solely examining the relationship between satisfaction (SAT), loyalty and behavioral intention (INT). Thus, there is a necessity for developing a more integrative model, especially the one including memorable tourism experience (MTE) when modeling the antecedents of loyalty and SAT. Kim' s (2018) study shows that destination image and MTEs affect future INTs both directly and indirectly through SAT. Same study demonstrated that MTE is the most effective determinant of the INT, as it was the case with the previous literature as well (Hudson and Brent Ritchie 2009; Kim 2014).

Since with MTE people make inferences of the unforgettable memories created at destination, which also affect their satisfaction it is considered as an important aspect in making destination as a special place for tourists (Kim and Stepchenkova 2017). In the previous literature, significant correlation between tourist experience and destination place attachment (DPA) was detected (Allan 2016; Backlund and Williams 2004; Hsu andScott 2020; Io andWan 2018), emphasizing that MTE places are those that meet the tourists' search for meaningful life and create feelings of belonging to the destination. Since attachment is the process of establishing an emotional bond with a place, those people who sensed it are also expected to have a high satisfaction level (Veasna et al. 2013). Accordingly, attachment is considered as antecedent of loyalty as well (Yuksel et al. 2010). When evaluating tourist experience at destination as a product, the level of loyalty can be measured by intentions such as repeat visits and suggestions to the one's close environment (Oppermann 2000). Finally, in the context of MTE it is possible to include the concept of destination brand personality (DBP) which provides a more complete assessment of brand experience. DBP was used in different studies to clearly show the tourists' commitment to a destination (Morgan et al. 2002; Morgan and Pritchard 2004), and its positive effect on satisfaction.

Considering the relations between MTEs, DBP and DPA, as well as their effect on SAT and INTs, it is considered useful to examine their non-linear relations in addition to linear ones. The behavioral patterns of travelers and entrepreneurial decision making depend on a variety of factors that create complexity patterns in their formulations (Pappas 2017b). Combination of linear and nonlinear analysis methods is recommended in order to increase the effectiveness of behavioral analysis (Russell and Faulkner 1999). Theory of complexity is applicable in examination of asymmetrical relations due to its complex characteristic propositions and orientations. This theory evolved from chaos theory and it's useful in complex system analysis (Seeger 2002), suggesting that small changes in behavior can 
also lead to significant differences (Pappas and Papatheodorou 2017). Complexity theory emphasizes that multi-element systems benefit predictability of behavior, while Chaos theory claims that simple systems generate complex unpredictable behavior patterns (Baggio 2008). Even though chaotic situations are complex and unpredictable and lead to dramatic conditions, the resulting dynamic systems cannot be fully controlled, while the relative order still exists (Nilson 1995; Zahra and Ryan 2007).

With this theory, besides simple behaviors produced by complex systems, higher-level models produced by simple interactions can also be defined (Fitzgerald and Eijnatten 2002). Theory of complexity was already used in analyzing tourist's purchasing behavior (Pappas 2017a; Pappas and Papatheodorou 2017; Wu et al. 2014) and explaining the decision-making process by applying an adequate assessment and explanation of behavioral characteristics and alternative combinations of asymmetric indicators (Pappas 2017a, b). Taking a predominantly reductionist approach, tourism researchers have been criticized for not using the chaos and complexity theory sufficiently to date (McDonald 2009), even though its application can provide important explanations for the formulation of behavioral models and the expression of the evolving dynamics of the tourist system (Russell and Faulkner 2004).

To sum up, purpose of the current study is to examine linear and non-linear relations based on the theoretical model consisting of MTEs, DBP, DPA, SAT and INTs such as positive word-of-mouth (WOM), recommendation and revisiting intentions. These relations were tested by combining regression and fsQCA. In this context, goals of the current study are derived as follows:

(1) To examine the effects on behavioral intention with a holistic model that connects psychological variables (MTEs, DBP, DPA and SAT).

(2) To inspect the mediating effects of variables such as DBP, DPA and SAT in this relationship by focusing on the linear effect of MTEs on behavioral intention.

(3) To examine the nonlinear effects of the configurations, which are formed by the combination of antecedents (conditions) and their effects, on behavioral intention.

(4) To show and compare linear and nonlinear relationships between variables in the proposed model analyzed with structural equation modelling (SEM) and fsQCA.

In the first part of the study, review of the related literature on direct and indirect effects of MTEs and proposed psychological variables is presented. Methodology part was devoted to explanation of data collection and analysis. Firstly, the symmetric effect of MTE, DBP, DPA and SAT in predicting intention of tourists was tested with regression model. Next, nonlinear effects of the configurations formed by the association of variables, which are the precursors of linear effects on INTs, were tested through fsQCA. Results and their implications were discussed in more detail in the concluding section of the article.

\section{Literature review and theoretical basis}

Kim (2018) criticizes the expectation-confirmation paradigm, which is frequently used to examine customer satisfaction in marketing research. A main critic is that in case of low expectations, there is no proof that it will lead to visitor's satisfaction or dissatisfaction. Therefore, the author emphasizes that satisfaction with low expectations should be discussed. In addition, due to the characteristics of tourism product, tourists have difficulties 
in evaluating it before visiting and experiencing destination (Kim 2018). Considering the ambiguous expectations of tourists, a satisfaction model based on spontaneous emotions and holistic experience, rather than traditional satisfaction paradigm based on the expectation-confirmation model, may be more relevant in tourism context (Zhong et al. 2017).

Memorable experience represents a rather long process as it involves remembrance of an entire trip from pre-planning stage, over on-site and recall stage, combined with the interpretation of the previous tourism experiences (Lee et al. 1994). Kim et al. (2012) emphasize that MTE is created by making selection of tourism experiences consisting of positive memories. In addition to product characteristics, researchers found that satisfaction, pleasant conversation, happiness, irritability, guilt and worry are part of memorable experiences as well (Larsen and Jenssen 2004; Wirtz et al. 2003). Kim et al. (2012) proposed that individuals often remember their tourism experiences with seven experiential components such as local culture, novelty, involvement, refreshment, hedonism, meaningfulness and knowledge, whereas other MTE models proposed elements such as surprising experiences, social interactions and performance of tour guides (Chandralal and Valenzuela 2015a, b).

It is stated that brand personality, which is formed by attributing human qualities to objects, creates symbolic effects for consumers (Aaker 1999). In tourism, this concept is used in the context of tourism destinations, where the personality characteristics of the destination, local people, accommodation facilities, restaurants and touristic places can be associated with the destination itself as human characteristics (Ekinci et al. 2007). While DBP stands out as personality traits that tourists will use as a way of expressing their emotional experiences, they actually become the distinctive features that distinguish the destination from its competitors. In addition, there is identification between DBP and the consumer's self-concept that has a positive effect on SAT (Murphy et al. 2007).

There is an emotional and value-based relationship with destinations, and destinations begin to make sense for visiting tourists. Place attachment, may be defined as a tourist's emotional attachment to a destination (Williams et al. 1992). Studies have found that place attachment has an impact on behavioral outcomes such as loyalty, WOM and visit intentions (Lee et al. 2012; Tsai 2012).

\subsection{Hypothesis development : direct effects}

DBP refers to the mental representation of the tourism experience and represents the symbolic attributes that may end up as attachment. Therefore, a DBP conveys the promise of a MTE (Brent Ritchie and Ritchie 1998) and results in stronger ties to the destination. Thus, the following hypothesis may be derived:

Hypothesis 1 Destination brand personality relates positively to destination place attachment.

Being in the tourist's memory, past experiences are valuable and trustable sources of information, providing the feeling of individual's sense of belonging (Backlund and Williams 2004; Hammitt et al. 2006; Io 2018). In the tourism context, place attachment reflects the commitment and loyalty in the tourist-destination relationship. In his study, Tsai (2016) stated that MTEs created through local food consumption reinforce the feelings of place attachment, which is supported by other studies as well (Hsu and Scott 2020; Sthapit et al. 2017). Studies conducted in another context show similar results: Allan (2016) found significant relationship between experience and place attachment 
among desert visitors, while Io and Wan (2018) also found same connection in the context of casino hotels. Therefore, following hypothesis was derived:

Hypothesis 2 Memorable tourism experience relates positively to destination place attachment.

The relationship between tourist experience and satisfaction has been highlighted in many studies. (Assaker and Hallak 2013; Huang et al. 2015; Oh et al. 2007; Ozdemir et al. 2012). Hosany and Witham (2010) found that experience dimensions have important effect on satisfaction of cruise tourists, while Chen and Chen (2010) found empirical evidence for the relationship between three dimensions of experience and SAT in the context of Taiwanese heritage sites. Aforementioned experiential tourism factors that contribute to SAT overlap with the dimensions of MTEs. In another study, a positive relationship was found between SAT and four dimensions of MTEs, such as affect, expectations, consequentiality, and recall (Tung and Brent Ritchie 2011). In the context of yoga tourism (Sharma and Nayak 2019) and ecotourism (Gohary et al. 2020) similar results were found. According to Zhong et al. (2017), MTEs positively affects SAT and through storytelling tourists are trying to keep this experience alive. Based on these propositions, following hypothesis was developed:

Hypothesis 3 Memorable tourism experience relates positively to satisfaction.

MTE, DBP and DPA emerge by the stimulation of certain emotions in the person. With the memorable experience based on pleasant memories, destinations become special and meaningful places for tourists. It is emphasized that MTE, which can be seen as a holistic experience that includes different travel experiences, are effective in the formation of DBP (Murphy et al. 2007; Seljeseth and Korneliussen 2015). Moreover, after examining the tourist experiences on travel blogs, Kim and Stepchenkova (2017) found that destination personality can be based on tourists' real experiences and that marketing activities could be conducted accordingly. Destination brands that reinforce the pleasant moments at destination and create memorable experiences (Brent Ritchie and Ritchie 1998), will also strengthen the sense of loyalty and place attachment among tourists. In the light of this information, the following hypothesis has been developed:

Hypothesis 4 Memorable tourism experience relates positively to destination brand personality.

Similarly, in the context of consumer products, brand experience has a positive impact on brand personality, loyalty and satisfaction (Brakus et al. 2009). When choosing destination, tourists bear in mind the similarities between destination personality and tourist himself/herself, as this positively affects satisfaction (Bekk et al. 2016). Therefore, destination personality is a concept that affects tourists' choice of destination and attitude towards it. It is predicted that MTE, DBP and DPA will lead to SAT and positive INT. Emotional and differentiating destination qualities are expected to reinforce satisfaction that forms the basis of tourist behavior studies. Considering the studies showing positive effect of destination personality on satisfaction (Bekk et al. 2016; Chen and Phou 2013; Chi et al. 2018; Hultman et al. 2015; Turkmen et al. 2018), the following hypothesis may be derived. 
Hypothesis 5 Destination brand personality relates positively to satisfaction.

Studies on place attachment help to understand tourist psychology and behavior (Dwyer et al. 2019). As destinations connect with tourists, they become extraordinary places loaded with symbolic meanings, enriching the meaning of the tourist's life (Tsai 2012). Since sense of belonging is the process of establishing a symbolic or emotional bond to the place, numerous studies showed that this feeling of place attachment will affect satisfaction (Abou-Shouk et al. 2018; Chow et al. 2019; Io 2018; Prayag and Ryan 2012; Prayag et al. 2018; Ramkissoon et al. 2013; Tlili and Amara 2016; Yuksel et al. 2010).

Hypothesis 6 Destination place attachment relates positively to satisfaction.

Feeling of satisfaction comes out when expectation related to tourist destination is met and directly affects the intention such as repeated purchase, WOM promotion and recommendation (Oliver 1999; Prayag et al. 2017), as well as destination choices (Abou-Shouk et al. 2018; Gohary et al. 2020; Hui et al. 2007). By summarizing all aforementioned, last hypothesis reflecting direct effects of the proposed variable combinations can be derived:

Hypothesis 7 Satisfaction relates positively to behavioral intention.

\subsection{Hypothesis development: indirect effects}

Sharma and Nayak (2019) revealed that MTEs have an indirect effect on INT through destination image and satisfaction. On the other hand, Gohary et al. (2020) stated that satisfaction has a mediating effect on the relationship between MTE and INT. It is emphasized that where there is a MTE, the search for meaning in tourists' lives is met and tourists have a sense of place attachment to that destination (Loureiro 2014; Vada et al. 2019). Moreover, Zhong et al.(2017) stated that MTEs are stronger predictors of place attachment than satisfaction.

Tlili and Amara (2016) stated that the positive emotions experienced during the tour reinforce the formation of place attachment and satisfaction. However, it is also known that satisfaction has a mediating effect on attachment and intention to travel (AbouShouk et al. 2018; Lo et al. 2019). In the study by Sthapit et al. (2017) it was shown that eating experiences are predictors of place attachment and INT, while MTE has mediating effect in the food consumption emotions and place attachment relationship.

Previous studies have shown that DBP has positive effect on SAT and INTs through attitudes (Souiden et al. 2017). There are studies empirically showing that brand personality has an intermediary role in the relationship between brand experience and loyalty in the context of consumer products (Ramaseshan and Stein 2014; Souiden et al. 2017). In addition, it was stated that the stronger the connection between the consumer and the product's brand personality, the stronger the consumer's loyalty and loyalty to the brand. All the aforementioned relations can be summarized in the following hypotheses regarding DBP and DPA:

Hypothesis 8 Destination brand personality has a mediating effect on the relationship between memorable tourism experience and satisfaction. 
Hypothesis 9 Destination place attachment has a mediating effect on the relationship between memorable tourism experience and satisfaction.

Hypothesis 10 Destination place attachment has a mediating effect on the relationship between destination brand personality and satisfaction.

It was found that adventure tourists perceive novel, emotional and well-planned tourism experiences as extremely precious, and, these experiences have significantly positive effect on INTs through satisfaction (Williams and Soutar 2009). Hosany et al. (2017) found that positive emotions underlie the meaningful experiences of tourists, and satisfaction mediates tourists' emotions and their behavioral intentions. Loureiro (2014) emphasized that memorable experiences in the context of rural tourism have a positive effect on place attachment and, consequently, on recommendation and revisit intention. In the light of the information provided, the mediating effects of place attachment, DBP and satisfaction in explaining the INTs of tourists by focusing on the MTE were tested with the following hypothesis:

Hypothesis 11 Satisfaction mediates the effect of memorable tourism experience on behavioral intention.

Hypothesis 12 Satisfaction has a mediating effect on the effect of destination brand personality on behavioral intention.

Hypothesis 13 Satisfaction has a mediating effect on the effect of destination place attachment on behavioral intention.

In addition to aforementioned indirect effects, it has been determined that MTEs also have significant effects on revisiting and WOM intention (Kim 2018; Kim and Brent Ritchie 2014). Kim and Brent Ritchie (2014) found that some elements of MTEs affected revisiting and WOM intention. While Huang et al. (2019) emphasize that MTEs at the food festival positively affected WOM and revisiting intentions, Adongo et al. (2015) supported the previous results on memorable local food experience positively affecting intention to involve in WOM. Based on these statements, following hypothesis was derived:

Hypothesis 14 Memorable tourism experience indirectly and positively relates to behavioral intention through the research model.

\section{Methodology}

Focusing on the relationship between MTE and INT, current study examines the linear and nonlinear effects of DBP, DPA and SAT in the scope of the proposed model. In the first phase of the study, regression logic and SEM method were used to test linear effects, while the nonlinear effects of the configurations formed by the associations of independent variables on the dependent variable were tested using the fsQCA. 


\subsection{Data collection and sampling}

Turkish tourists coming to domestic destination Antalya, known as one of the most popular mass tourism destinations in Turkey and abroad, were selected as the target study population. According to the statistics, in 2019 there were 121.711 Turkish visitors in Antalya (Antalya Provincial Culture and Tourism Directorate 2019). In order to reach a representative group, data were collected from tourists who had their vacation in a 5-star city center hotel between May-July 2019. Tourists were reached by convenience sampling during their check-out process from the hotel. After obtaining permissions from the responsible hotel managers, data were collected from 470 tourists who voluntarily participated in the survey. In total 452 questionnaires were suitable for use in the study. According to the table of sample sizes for large populations developed by Krejcie and Morgan (1970) and taking into account 95\% confidence level and 5\% error margin, sample size for a population of 75,000 and above is 382, which implies that the sample used in current study is appropriate.

\subsection{Measures}

Within the scope of the research, questions in the survey were related to the measurement of MTE, DBP, DPA, SAT and INT. Scales valid from previous studies were defined and adapted to the current research setting. Measurement tool consists of 5 variables with 28 expressions measured with 7-point Likert type scale (Table 2). MTE scale was applied from Kim' s (2018) study, while measurement tool from Yuksel et al.'s (2010) study was used for DPA. In addition, combination of the Aaker' s (1997) and Chi et al. (2018) scales, as well as focus group interviews with tourism professionals in the region, were used for measuring DBP. This measurement tool consisted of 11 statements in total. Finally, overall satisfaction was adapted from Zhong et al.'s (2017) study, and, behavioral intention measurement was adapted from Loureiro's (2014) study. Finally, questionnaire was concluded with questions about demographic characteristics.

\section{Results}

\subsection{Sample}

According to descriptive statistical data (Table 1), 13.7\% of the participants were aged $16-25,37.8 \% 26-35,32.5 \% 36-45,11.7 \% 46-55$ and $4.2 \% 56$ and above, while $51.1 \%$ of the participants are male and $48.9 \%$ are female. When observing educational level of participants, the majority of them have university degree $(60.9 \%)$. When it comes to marital status $41.4 \%$ are single, while $58.6 \%$ are married. $73.5 \%$ of tourists have visited Antalya before, $26.5 \%$ of participants were first time visitors with $50.7 \%$ of the participants who spent their holiday with 1-2 people. 
Table 1 Respondents' Profile (n: 452)

\begin{tabular}{|c|c|c|}
\hline & $\begin{array}{l}\text { Number of } \\
\text { respondents }\end{array}$ & $\%$ \\
\hline \multicolumn{3}{|l|}{ Age } \\
\hline $16-25$ & 62 & 13.7 \\
\hline $26-35$ & 171 & 37.8 \\
\hline $36-45$ & 147 & 32.5 \\
\hline $46-55$ & 53 & 11.7 \\
\hline 56 and above & 19 & 4.2 \\
\hline \multicolumn{3}{|l|}{ Gender } \\
\hline Male & 231 & 51.1 \\
\hline Female & 221 & 48.9 \\
\hline \multicolumn{3}{|l|}{ Education } \\
\hline Primary\& Secondary school & 8 & 1.8 \\
\hline High school & 108 & 23.9 \\
\hline University & 274 & 60.6 \\
\hline Master's degree & 49 & 10.8 \\
\hline $\mathrm{PhD}$ degree & 13 & 2.9 \\
\hline \multicolumn{3}{|l|}{ Marital status } \\
\hline Single or divorced & 187 & 41.4 \\
\hline Married & 265 & 58.6 \\
\hline \multicolumn{3}{|l|}{ The number of visit to Antalya } \\
\hline First visit & 120 & 26.5 \\
\hline Visited Antalya before & 332 & 73.5 \\
\hline \multicolumn{3}{|c|}{ The number of people on holiday together } \\
\hline $1-2$ & 229 & 50.7 \\
\hline $3-4$ & 161 & 35.6 \\
\hline 5-6 & 52 & 11.5 \\
\hline $6+$ & 23 & 5.1 \\
\hline
\end{tabular}

\subsection{Confirmatory factor analysis}

The results of validity and reliability analysis of all scales are presented in Table 2 . Based on the confirmatory factor analysis, statistics related to scale measures indicate good fit values. Cronbach alpha, AVE and CR values of the scales are at valid levels and all scales meet the appropriate conditions for taking part in the SEM (Table 2).

The relationship between scales, and basic demographic and descriptive indicators was questioned through correlation analysis. According to the obtained results, while gender only shows a meaningful relationship with satisfaction and intention, age shows a significant relationship with MTE, DBP, SAT and INT. Marital status is related to MTE, DBP, and intention. On the other hand, having traveled to Antalya before is associated with a higher rate of MTE, DBP, SAT and INT than all other demographic variables. There was no statistically significant relationship found between DPA and descriptive variables. 


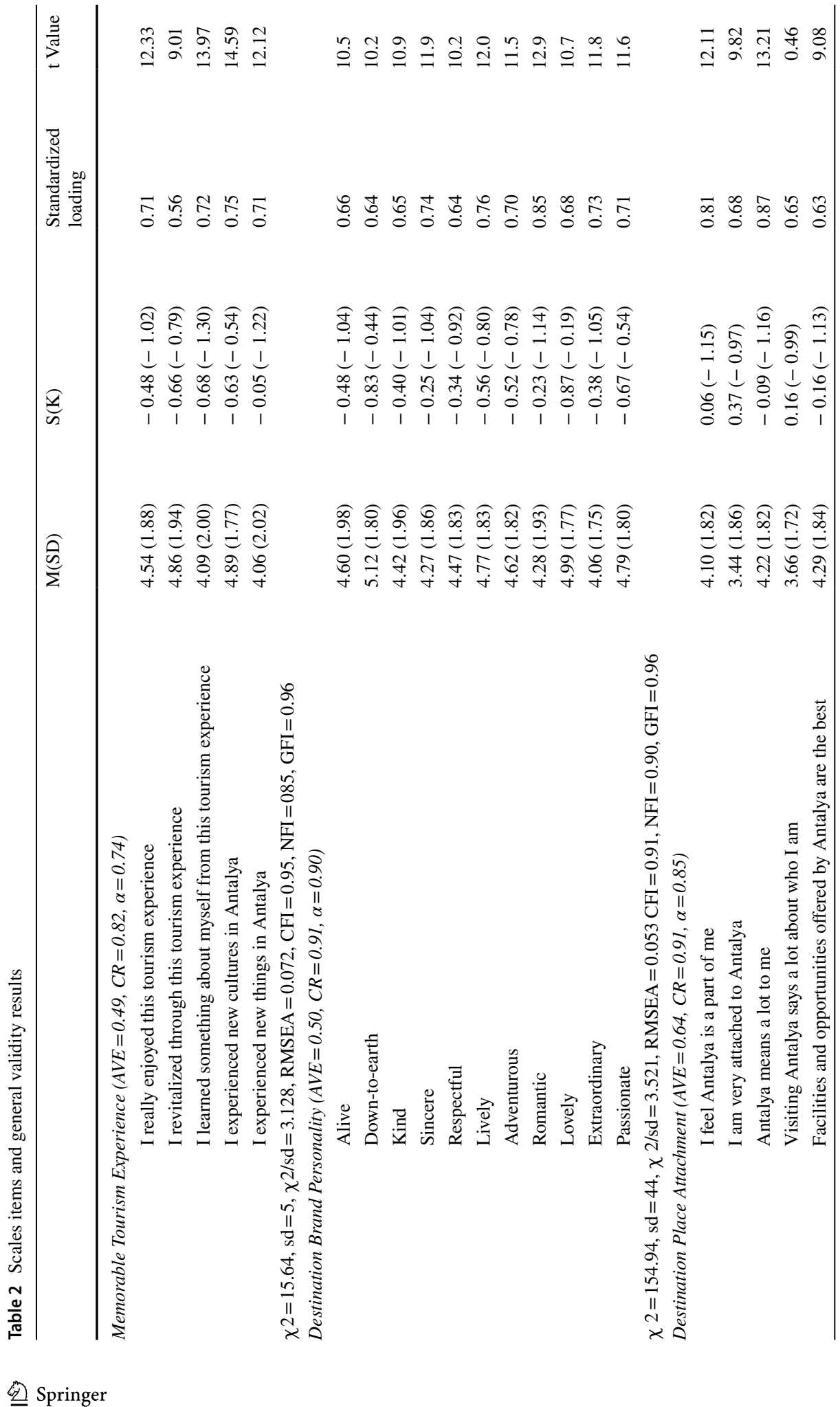




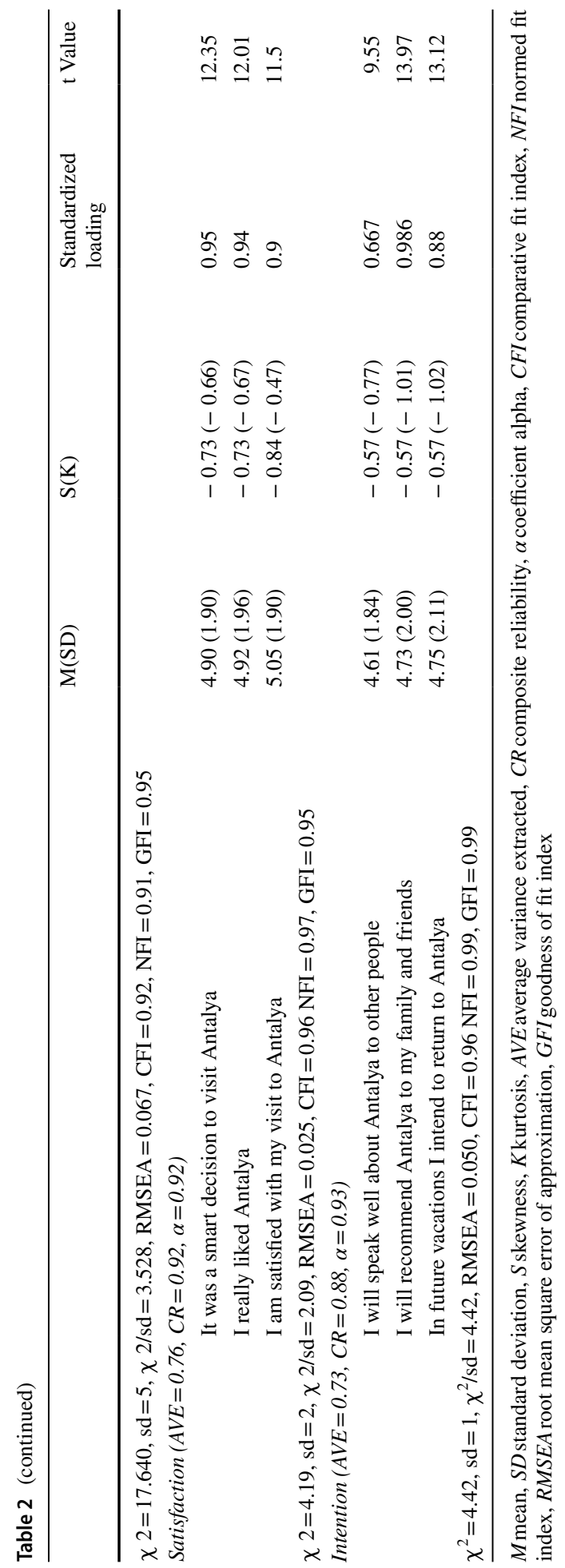


Table 3 Results of HTMT analysis

\begin{tabular}{llllll}
\hline & DBP & DPA & INT & MTE & SAT \\
\hline DBP & & & & & \\
DPA & 0.314 & & & & \\
INT & 0.676 & 0.224 & & & \\
MTE & 0.654 & 0.240 & 0.659 & & \\
SAT & 0.651 & 0.423 & 0.700 & 0.659 & \\
\hline
\end{tabular}

\subsection{Phase 1- examining linear relations: hypothesis tests with SEM}

The fit of the five-factor measurement model and the relationships in the structural model were tested with the two-step approach of Anderson and Gerbing (1988). Before the structural model analysis; the criterion of "Heterotrait-Monotrait (HTMT)" was used to examine the discriminant validity of the scales. This criterion indicates the similarity levels of the dimensions in the scale. As the intersection points of the dimensions move away from 1 and approach 0 , the discriminant validity increases and this value is expected to be below 0.9 (Hair et al., 2017). The results obtained from the study show that none of the intersection points were higher than 0.7 , therefore discriminant validity was ensured (Table 3 ).

In the first stage, the measurement model was examined in terms of validity and reliability using confirmatory factor analysis. The SEM was used to evaluate the connections in the structural model. Smart PLS program was used for SEM. Model fit statistics were reported in Table 2. All fit indices indicate a high level of model fit in measurement model (Sharma et al. 2005) (Table 4).

Gender, marital status, previous visits to Antalya and age were determined as control variables, based on the assumption that they significantly affect the relationships in the study. After comparing the measurement model $\left(\chi^{2}=1.197,201, \mathrm{df}=317\right)$ with the structural model without control variables $\left(\chi^{2}=1.417,612, \mathrm{df}=321\right)$, it was determined that the model created was consistent and significantly different $\left(\Delta \chi^{2}=220,411\right.$, $\left.\mathrm{df}=4, p<0.05\right)$. According to the results, the best explanation model is the partial mediation model, while the full mediation model is the model with the lowest explanation (Table 5). For this reason, the partial mediation model was taken as a reference in the scope of the current study.

Analysis results show that all hypotheses developed for the model were statistically significant (Fig. 1). MTE has a significant effect on DBP $(\beta=0.632, \mathrm{t}=21.00, p<0.05$, supporting hyp. 4) as well as on satisfaction $(\beta=0.417, \mathrm{t}=9.20, p<0.05$, supporting hyp. 3 ) and DPA $(\beta=0.256, \mathrm{t}=4.71, \mathrm{p}<0.05$, supporting hyp. 2$)$. DBP has statistically significant effect of on satisfaction $(\beta=0.320, \mathrm{t}=6.75, p<0.05$, supporting hyp. 5) and DPA $(\beta=0.274, \mathrm{t}=7.30, p<0.05$, supporting hyp.1), while also partial mediating role in the relationship between MTE and satisfaction was confirmed $(\mathrm{t}=6.62, p<0.05$, supporting hyp. 8). Similarly, DPA has statistically significant effect on satisfaction $(\beta=0.275, t=4.54, p<0.05$, supporting hyp. 6$)$, and partial mediating role in the relationship between MTE and satisfaction $(t=3.59, p<0.05$, supporting hyp. 9). DPA also has statistically significant partial mediating role in the effect of DBP on satisfaction $(\mathrm{t}=3.72, p<0.05$, supporting hyp. 10). Satisfaction has a significant effect on intention $(\beta=0.741, \mathrm{t}=28.11, p<0.05$, supporting hyp. 7$)$, as well as statistically significant mediating role in the effect of MTE on intention $(\mathrm{t}=8.54, p<0.05$, supporting hyp. 11). Furthermore, satisfaction has a statistically significant mediating role in the effect of DBP $(\mathrm{t}=6.69, p<0.05$, supporting hyp. 12) and DPA on intention $(\mathrm{t}=4.6, p<0.05$, 


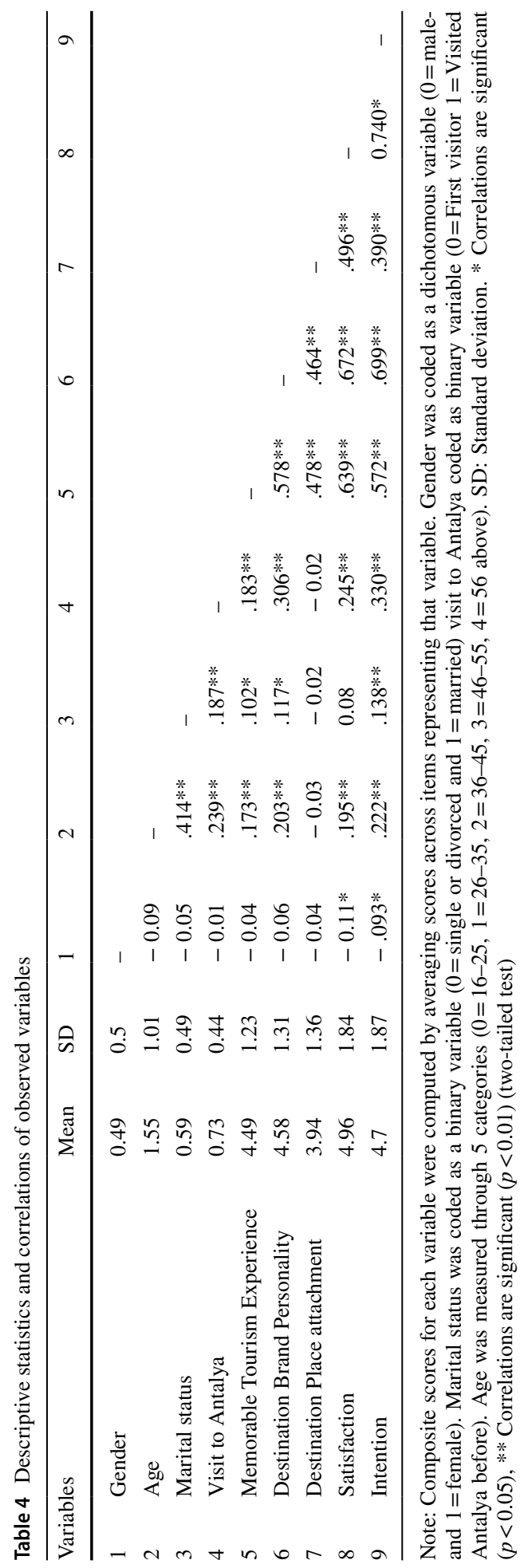




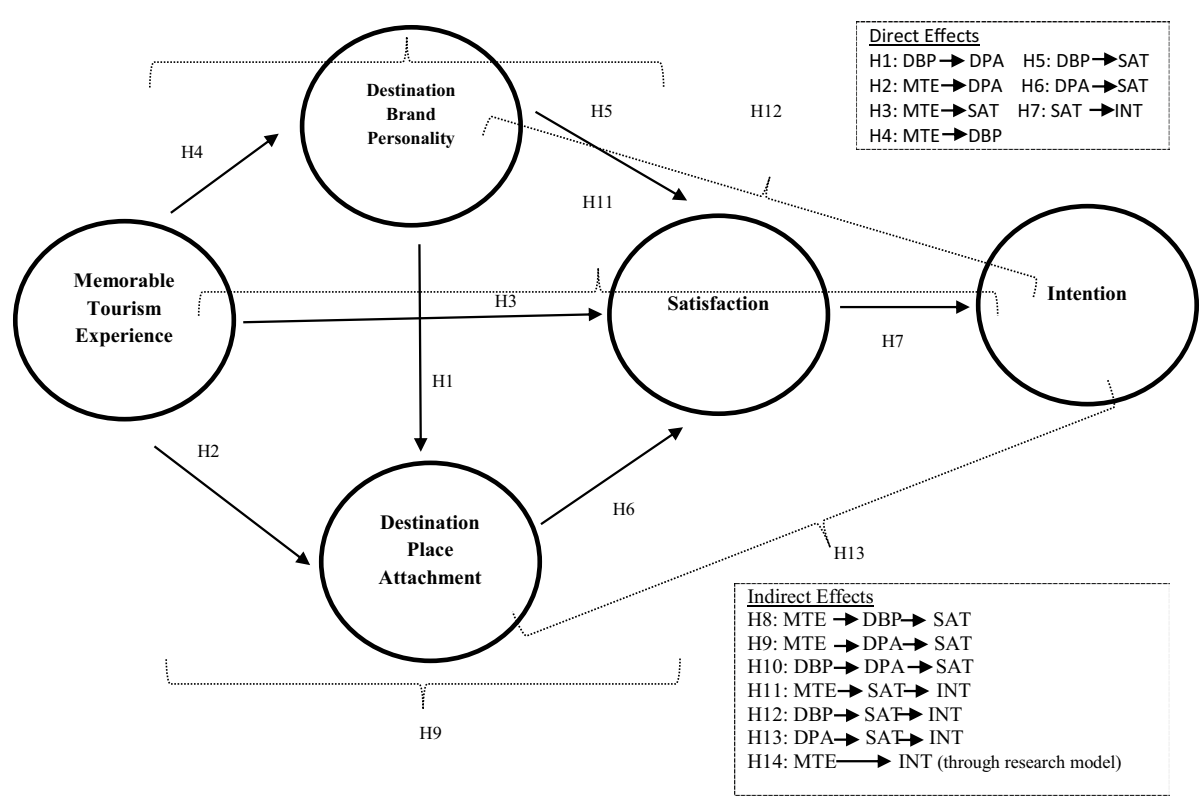

Fig. 1 Structural Model

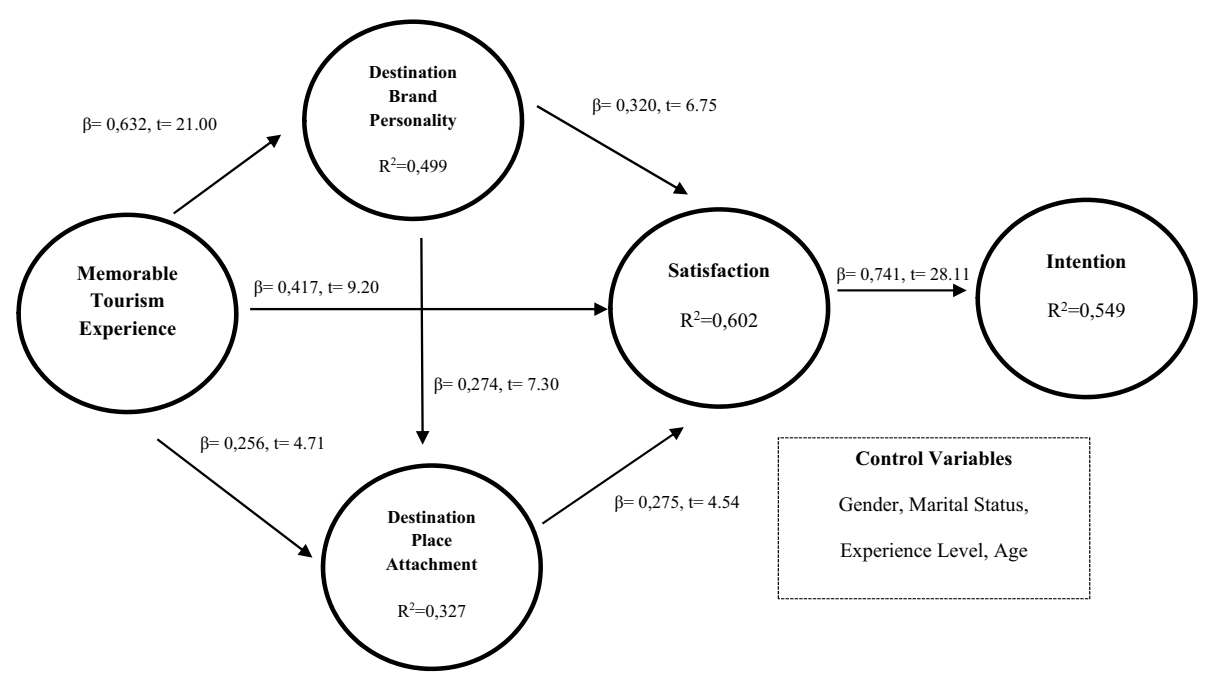

Fig. 2 Model test results

supporting hyp. 13). Therefore, regarding the indirect relationship between MTE and intention, the mediating role of satisfaction through the accepted research model was also confirmed ( $\mathrm{t}=8.54, p<0.05$, supporting hyp. 14) (Fig. 2). 
The amount of deviation found in the variance ratio distribution of the items is evaluated with the Harmans single factor test. According to this test result, the explanation ratio of the first component in all observed variables included in the exploratory factor analysis is below 50\%, indicating that there will be no common method bias in the SEM. As a result of the factor analysis made with all observed variables included in the scope of the study, the explanation rate of the first component was determined as $41.32 \%$.

On the other hand, in the relation between implicit variables in the SEM, VIF value greater than 3.3 is an indicator of pathological linearity and that a model is distorted by common method bias. Therefore, as shown in Table 6, if all (factor level) VIFs are equal to or below 3.3 in the results of the collinearity test, the model can be evaluated independently from common method bias (Kock 2015). According to the results obtained within the scope of the study; VIF values in all relations are below 3.3 and it has been determined that the model was not contaminated by common method bias.

\subsection{Phase 2- examining nonlinear relations with fsQCA}

To explain the complexity between variables in the model, fsQCA was used. This method examines the possible sets of multiple combinations generated from the describing variables that are expected to affect the target variable (Longest and Vaisey 2008). fsQCA method is often used in case studies and can be applied to both qualitative and quantitative data. (Longest and Vaisey 2008; Ragin 2000). fsQCA works with the complexity theory logic, which accepts that different results can be produced with alternative feature combinations for predicting the absence and existence of certain conditions

Table 5 Results of Model Comparison

\begin{tabular}{|c|c|c|c|c|c|c|c|c|c|}
\hline Models & $\chi^{2}$ & $\mathrm{df}$ & $\Delta \chi^{2}$ & $\mathrm{df}$ & $\mathrm{MC}$ & CFI & RMSEA & NFI & SRMR \\
\hline $\begin{array}{l}\text { I. Hypothesized model } \\
\text { (partially mediated } \\
\text { model) }\end{array}$ & 1197.201 & 317 & - & - & - & 0.90 & 0.65 & 0.87 & 0.052 \\
\hline \multicolumn{10}{|l|}{$\mathrm{MTE} \rightarrow \mathrm{DBP}, \mathrm{DPA}, \mathrm{SAT}$} \\
\hline \multicolumn{10}{|l|}{$\mathrm{DBP} \rightarrow \mathrm{DPA}, \mathrm{SAT}$} \\
\hline \multicolumn{10}{|l|}{$\mathrm{DPA} \rightarrow \mathrm{SAT}$} \\
\hline \multicolumn{10}{|l|}{$\mathrm{SAT} \rightarrow \mathrm{INT}$} \\
\hline II. Fully mediated model & 1456.952 & 319 & 259.51 & 2 & I and II & 0.89 & 0.76 & 0.71 & 0.086 \\
\hline \multicolumn{10}{|l|}{$\mathrm{MTE} \rightarrow \mathrm{DBP}, \mathrm{DPA}$} \\
\hline \multicolumn{10}{|l|}{$\mathrm{DBP} \rightarrow \mathrm{SAT}$} \\
\hline \multicolumn{10}{|l|}{$\mathrm{DPA} \rightarrow \mathrm{SAT}$} \\
\hline \multicolumn{10}{|l|}{$\mathrm{SAT} \rightarrow \mathrm{INT}$} \\
\hline \multicolumn{10}{|l|}{ III. Non-mediated model } \\
\hline $\mathrm{MTE} \rightarrow \mathrm{SAT}$ & 1589.234 & 320 & 392.033 & 3 & I and III & 0.85 & 0.78 & 0.71 & 0.141 \\
\hline \multicolumn{10}{|l|}{$\mathrm{DBP} \rightarrow \mathrm{SAT}$} \\
\hline \multicolumn{10}{|l|}{$\mathrm{DPA} \rightarrow \mathrm{SAT}$} \\
\hline $\mathrm{SAT} \rightarrow \mathrm{INT}$ & & & & & & & & & \\
\hline
\end{tabular}

Note: The control variables were included in the analysis. The hypothesized model was the best-fitting model. $\mathrm{MTE}=$ Memorable Tourism Experience; DBP $=$ Destination Brand Personality; DPA=Destination Place Attachment; SAT =Satisfaction; INT =Behavioral Intention; $\mathrm{MC}=$ Model comparison; $\mathrm{CFI}=$ Comparative fit index; $\mathrm{NFI}=$ Normed fit index; RMSEA = Root means square error of approximation; $\mathrm{SRMR}=$ Standardized root mean square residual 
Table 6 Structural model results

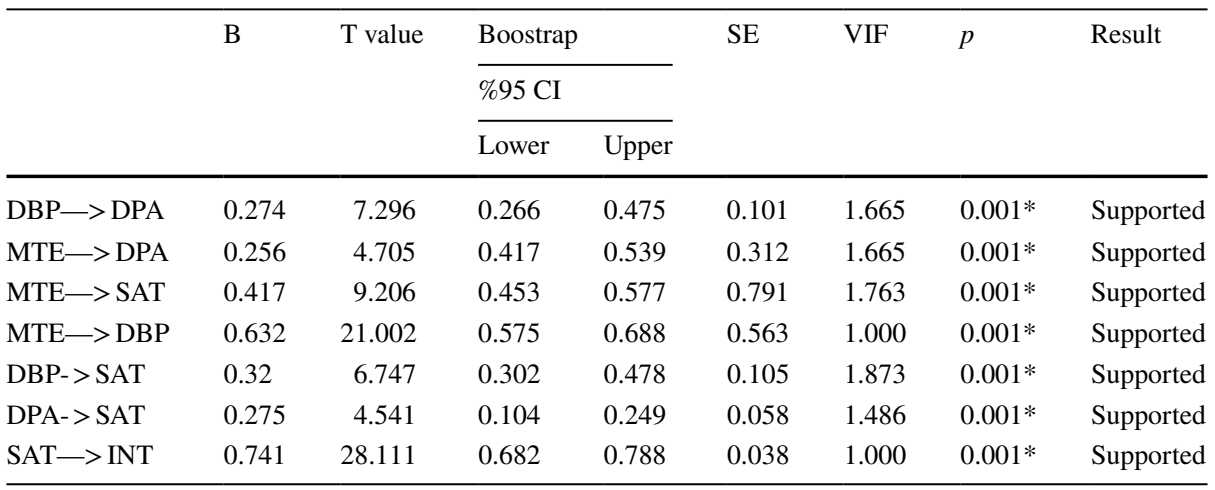

Table 7 Descriptive statistic

\begin{tabular}{lllllll}
\hline Variable & Mean & SD & Minimum & Maximum & N Cases & Missing \\
\hline MTE & 0.595 & 0.245 & 0.08 & 0.95 & 452 & 0 \\
DBP & 0.617 & 0.253 & 0.06 & 0.96 & 452 & 0 \\
DPA & 0.488 & 0.264 & 0.05 & 0.95 & 452 & 0 \\
SAT & 0.668 & 0.309 & 0.08 & 0.95 & 452 & 0 \\
INT & 0.624 & 0.327 & 0.05 & 0.95 & 452 & 0 \\
\hline
\end{tabular}

(Kent and Argouslidis 2005; Woodside and Zhang 2013). The method also predicts the rejected and the accepted clusters for the absence or presence of a particular condition (Woodside and Zhang 2013). In set theory, the consistency of a certain causal relationship and the absence and existence of a certain condition are accepted and calculated by the following formula (Skarmeas et al. 2014; Ordanini et al. 2014):

$$
\text { Consistency }_{\text {Sufficient Conditions }\left(X_{i} \leq Y_{i}\right)}=\frac{\sum_{i=1}^{I} \min \left(X_{i}, Y_{i}\right)}{\sum_{i=1}^{I} X_{i}}
$$

where $\mathrm{X}$ stands for score of the conditions in the configuration, while $\mathrm{Y}$ is the result score. This consistency calculation is important for the 'truth table' (Table 8). Descriptive statistical functions are tools for obtaining a quick overview of a data set's conditions and result category. Descriptive statistics tools are useful for gathering first impressions of a dataset and help in reflecting how fuzzy membership scores are assigned, applying changes as needed and tracking those changes in data. Thus, when examining Table 7 it can be concluded that the averages are not very low and SAT is necessary for predicting INT $(0.624 \leq 0.668)$, whereas MTE $(0.624 \geq 0.595)$, DBP $(0.624 \geq 0.617)$, DPA $(0.624 \geq 0.488)$ are sufficient for predicting INT. Likewise, the XY graph used in the program serves as a tool to quickly inspect the determined relationships between causal conditions and outcome. In this context, $\mathrm{XY}$ graph indicates a relation of high sufficiency (consistency for $Y \geq X: 0.844$ ) and necessity (consistency for $Y \leq X: 0.805$ ) between INT and MTE; a high sufficiency (consistency for $Y \geq X$ : 0.853 ) and an average necessity (consistency for $\mathrm{Y} \leq \mathrm{X}: 0.667$ ) between INT and DPA; a high sufficiency (consistency for $\mathrm{Y} \geq \mathrm{X}: 0.856$ ) and 
necessity (consistency for $\mathrm{Y} \leq \mathrm{X}$ : 0.917 ) between INT and SAT; a high sufficiency (consistency for $Y \geq X: 0.864$ ) and necessity (consistency for $Y \leq X$ : 0.855 ) between INT and DBP. In light of these findings, these four conditions were used in the evaluation of the intention result.

The truth table is made of data matrix, which describes states in terms of conditions and outcome, but the data is structured differently in these tables. Rows in data matrix refer to the assigned membership points for one condition. In contrast, the truth table rows describe the result for every possible combination of existing and nonexistent conditions for all cases containing that combination. It provides the definition of subset relationships by presenting the truth table data. In these relationships, conditions with a certain configuration exhibit the same result. In these cases, the configuration can be considered sufficient for the result and defines that the same time lines are sufficient. As a result of the 4 conditions dealt in current study (MTE, DPA, SAT, DBP) $2^{4}=16$ configuration emerged. However, as shown in the Table 8, while 12 configurations were kept, 4 configurations were left out from the analysis. Two of these configurations qualify as "limited diversity," as Ragin and Becker (1992) put it they are limited to practically all variations of empirical situations and are excluded from the analysis due to their tendency to cluster across certain dimensions. The other two configurations are considered to be low-value in large-population studies numbers (such as number: 2-3) (Ragin 2008) and these are excluded from the analysis. As for the consistency values, values less than 0.8 are processed as 0 and high values as 1 for the result (INT) (Ragin 2008). The ultimate importance of sufficient truth table rows is that they make logical minimization for the configurations in Table 8.

Table 9 contains important information on the output. On the left, the causal methods remaining after the minimization process are listed. Alternatives to the result are combinations of conditions that contain sufficient means. The first column shows the raw coverage of each method, i.e. to what extent each method can explain the result. The second column shows the unique coverage of methods, that is, the proportion of cases that can only be explained by this method. Finally, last column shows consistency points of each method. Below the list of causal methods is the consistency and solution coverage. If the consistency or coverage scores for the solution are less than 0.80 for fuzzy sets, this indicates a poorly defined model. The solution coverage in the study is 0.869 , showing that

Table 8 Truth table ideal type configurations

\begin{tabular}{llllclll}
\hline MTE & DPA & SAT & DBP & Number & INT & Raw consistency & PRI consistency \\
\hline 1 & 1 & 1 & 1 & 150 & 1 & 0.953 & 0.927 \\
0 & 1 & 1 & 1 & 9 & 1 & 0.951 & 0.873 \\
1 & 0 & 1 & 1 & 67 & 1 & 0.935 & 0.874 \\
0 & 0 & 1 & 1 & 27 & 1 & 0.928 & 0.823 \\
0 & 1 & 1 & 0 & 8 & 1 & 0.902 & 0.693 \\
1 & 0 & 1 & 0 & 10 & 1 & 0.901 & 0.733 \\
0 & 0 & 1 & 0 & 7 & 1 & 0.893 & 0.679 \\
1 & 0 & 0 & 1 & 7 & 1 & 0.853 & 0.554 \\
0 & 0 & 0 & 1 & 16 & 0 & 0.798 & 0.406 \\
1 & 0 & 0 & 0 & 15 & 0 & 0.775 & 0.367 \\
0 & 1 & 0 & 0 & 22 & 0 & 0.749 & 0.252 \\
0 & 0 & 0 & 0 & 45 & 0 & 0.641 & 0.199 \\
\hline
\end{tabular}


many situations where the result is present are members of any method and therefore can be explained by the model. Solution consistency of 0.865 shows that the combined consistency of causal methods is good. Accordingly, low DPA and SAT ( DPA*SAT) are affecting INT. While consistency of this solution in 0.881 it affects the solution at the level of 0.515. High SAT and low MTEs as well as high SAT and high DBP are affecting intention. Especially high SAT and DBP are describing the intention in the best way with raw coverage of 0.822 . Lastly, high MTEs, low DPA and high DBP are significantly affecting intention. To summarize, even if the DPA is not present, intention will be affected if the other conditions are present. In case of satisfaction the presence of other conditions will not negatively affect the intention but just the degrees of the impact will change. On the other hand, DBP affects the intention together with the other conditions.

\section{Discussion and conclusion}

Results of the current study show that all proposed psychological variables are affecting tourist intentions in both symmetrical and asymmetrical model. Thus, both linear and non-linear relations between MTE, DBP, DPA, SAT and INT were clearly shown through regression and fsQCA analysis. The existence of the linear relationship between all psychological variables inside the model showing MTE as the most effective variable on SAT was supported. Positive correlation between MTE and DBP was also found in the current study. Moreover, DBP has partially mediating role in the relation between MTE and SAT. Besides positive effect on MTE, DPA also has partial mediating role in MTE-SAT relation. When asymmetric relation is being examined ( DPA*SAT) and (MTE* $\sim$ DPA*DBP) combinations affect INTs. fsQCA results classify SAT as necessary for the INT and MTE, DPA and DBP as sufficient conditions. MTE found its place in two of the possible multiple combination sets produced from the explaining variables expected to affect the target variable. It is seen from the study results that INTs among Turkish tourists are affected the most by the combination of high satisfaction and DBP. These results correspond to those of the previous studies that found positive relation between SAT of MTEs and INTs (Gohary et al. 2020; Kim 2018; Kim et al. 2010; Sharma and Nayak 2019). fsQCA results (MTE* $\sim$ DPA*DBP) also showed that combination of three variables affect INTs. In other words, combination of high MTE and DBP and even low level of DPA represent an influential combination on INTs among tourists. Related studies in the tourism literature have shown that DBP can be formed upon MTEs, and can be used as a self-expressing tool, as when mediated

Table 9 Sufficient combinations of conditions for behavioral intention

\begin{tabular}{llll}
\hline Causal configuration & Raw coverage & Unique coverage & Consistency \\
\hline$\sim$ DPA*SAT & 0.515 & 0.018 & 0.881 \\
$\sim$ MTE*SAT & 0.395 & 0.005 & 0.884 \\
SAT*DBP & 0.822 & 0.297 & 0.920 \\
MTE* $\sim$ DPA*DBP & 0.458 & 0.011 & 0.885 \\
Solution coverage: 0.869 & Solution consistency: & & \\
& 0.865 & & \\
\hline
\end{tabular}


through self-congruity, it has positive effect on revisiting and recommendation intentions (Usakli and Baloglu 2011).

Generally, obtained results show that MTE is significantly affecting SAT, supporting the previous results in the literature (Huang et al. 2015; Kim et al. 2012; Martín-Santana et al. 2017). In addition, with the fsQCA model it was shown that combination of DBP and SAT have the highest impact on INTs. This research reveals that MTE significantly affect tourists' overall impressions of a destination, by examining their linear and nonlinear relationship with psychological variables such as MTE, DBP and DPA. In addition, consisted with the results of the previous studies (Beerli and Martín 2004; Chen and Phou 2013; Hallmann et al. 2015; Prayag et al. 2017), causal relation between SAT and INT is confirmed. In addition, it shows the indirect effect of MTE on DBP, DPA and SAT.

Theoretically, this article contributes to understanding the symmetrical and asymmetrical relationships of some factors that affect the behavioral intentions of tourists. MTE, DBP and DPA emerge inside the individual with the stimulation of certain emotions. For this reason, these concepts, which can be seen as unique processes, may help us understand the travel decision-making of modern tourist. Yet, no previous study has examined the four loyalty premises by focusing on MTE. Firstly, results reinforce the previous findings about positive effects of MTEs on future behavior while adding the evidence of its effect on intentions through or in combination with DBP, DPA and SAT. From methodological perspective, this study is among the first in tourism and service field that uses fsQCA, regression analysis and SEM application, to combine symmetrical and asymmetric relationships between variables in the model.

Current study was conducted in the context of Turkish domestic' travel experiences, which is in line with The World Tourism Organization's (2020) emphasis on domestic tourism's ability to help destinations recovering from the social and economic damages of COVID-19 pandemic. Comprehensive understanding of domestic MTEs' structure may broaden perspectives upon more sustainable and durable tourism models. Moreover, asymmetric analysis may provide an alternative insight to complex phenomena such as impacts of COVID-19 on tourism and enlighten complex tourist decision-making process in times of crisis.

Several practical implications can be derived. Besides making their initial search on destinations through online channels such as blogs, official websites and social media platforms, nowadays tourists also share their experiences in online environment as well (Chandralal et al. 2015a, b). Since MTEs reinforce the intention of tourists to share these experiences on social media (Wong et al. 2020), it is vital for destination management stakeholders to plan and successfully manage promising features of destination experiences and brand personality in online domain. Words and phrases used in the online content should be in compliance or even reinforce the desired DBP (Vinyals-Mirabent et al. 2019). While travel experiences shared on social media can be helpful in decreasing negative perception of DBP, this content can also affect destination choice among potential visitors (Sultan et al. 2019).

It is known that past experiences influence consumers' purchasing decisions (Kronlund et al. 2008). This study shows that visitors who find their experience memorable are more satisfied and intend to revisit their destination. If kept memorable, these experiences can lead to repeating visits to destination and they will be a major step forward towards creating customer value. Destination managers should develop marketing communication programs by focusing on the psychological variables used in this research in order to create a competitive advantage and establish more sustainable functioning of tourism destinations. 


\subsection{Limitations and recommendations for further research}

Results of this study should be evaluated with some limitations. First, this study focuses on domestic Turkish tourists who visited the city of Antalya. It can be suggested to work in different contexts and cultures to expand the findings of this study. This research model or a further expanded model could be tested on foreign visitors' context in order to check its validity and invariance. For example, different underlying dimensions of MTEs, destination images, or other psychological variables may appear for tourists' during the COVID-19 process. Understanding these may enhance destination's touristic appeal during period of crises. In addition, focus was on psychological variables that affect the tourist intentions, but the sub-dimensions of MTE, DPA, and DBP variables can be further derived and the relationships between these can be examined in more detail. Moreover, the effects of the variables used in the current study can be analyzed in another model, where destination image will be the target variable, or the existing one can be extended with other determinants of tourist loyalty.

Finally, from a methodological point of view, this study brought SEM and fsQCA together to expand the results derived from a measurement model. Alternative research methodologies could bring different and useful inferences that may help tourist destinations in understanding the relationship between memorable tourism experience and desired tourist behavioral patterns.

Acknowledgements Data of this study was obtained from the Master Thesis of second author.

Authors' contribution Beykan Çizel: Conceptualization, methodology, supervision. Ismail Gökay Kırtıl: Data collection, writing. Volkan Aşkun: Conceptualization, formal analysis. Edina Ajanovic: Writing- original draft, writing — review \& editing. Hatice Karakaş: Formal analysis.

Funding This research did not receive any specific grant from funding agencies in the public, commercial, or not-for-profit sectors.

Declaration

Conflict of interest The author(s) declare that they have no competing interests.

\section{References}

AakerJ, L.: Dimensions of brand personality. J. Mark. Res. 34(3), 347-356 (1997)

AakerJ, L.: The malleable self: the role of self-expression in persuasion. J. Mark. Res. 36(1), 45-57 (1999)

Abou-Shouk, M.A., Zoair, N., El-Barbary, M.N., et al.: Sense of place relationship with tourist satisfaction and intentional revisit: evidence from Egypt. Int. J. Tour. Res. 20(2), 172-181 (2018)

AdongoCA, A.S.W., Dayour, F.: Will they tell others to taste? International tourists' experience of Ghanaian cuisines. Tour. Manag. Perspect. 15, 57-64 (2015)

Allan, M.: Place attachment and tourist experience in the context of desert tourism-the case of Wadi Rum. Czech J. Tour. 5(1), 35-52 (2016)

Anderson, J.C., Gerbing, D.W.: Structural equation modeling in practice: are view and recommended twostep approach. Psychol. Bull. 103(3), 411-423 (1988)

Antalya Provincial Culture and Tourism Directorate (2019) Tourism statistics. https://is.kultur.gov.tr/ktbyi gm/public/login.xhtml Accessed 10 Nov 2019

Assaker, G., Hallak, R.: Moderating effects of tourists' novelty-seeking tendencies on destination image, visitor satisfaction, and short- and long-term revisit intentions. J. Travel Res. 52(5), 600-613 (2013) 
Backlund, E.A., Williams, D.R.: A quantitative synthesis of place attachment research: investigating past experience and place attachment. In: Proceedings of the 2003 Northeastern Recreation Research Symposium (ed J Murdy), New York, US, pp. 320-325. New York: US Department of Agriculture, Forest Service, Northeast Research Station (2004)

Baggio, R.: Symptoms of complexity in a tourism system. Tour. Anal. 13(1), 1-20 (2008)

Beerli, A., Martín, J.D.: Factors influencing destination image. Ann. Tour. Res. 31(3), 657-681 (2004)

BekkM, S.M., Kruse, J.: The benefits of similarity between tourist and destination personality. J. Travel Res. 55(8), 1008-1021 (2016)

BrakusJJ, SchmittBH., Zarantonello, L.: Brand experience: what is it? How is it measured? Does it affect loyalty? J. Mark. 73(3), 52-68 (2009)

Brent Ritchie, J.R., Ritchie, R.J.B.: The branding of tourism destinations: past achievements and future challenges. In: Annual congress of the international association of scientific experts in tourism, Marrakech, Morocco, pp. 1-31 (1998)

ChandralalL, R.J., Valenzuela, F.R.: An application of travel blog narratives to explore memorable tourism experiences. Asia Pac. J. Tour. Res. 20(6), 680-693 (2015)

Chandralal, L., Valenzuela, F.R.: Memorable tourism experiences: scale development. Contemp. Manag. Res. 11(3), 291-310 (2015)

Chen, C.F., Chen, F.S.: Experience quality, perceived value, satisfaction and behavioral intentions for heritage tourists. Tour. Manag. 31(1), 29-35 (2010)

Chen, C.F., Phou, S.: A closer look at destination: image, personality, relationship and loyalty. Tour. Manag. 36, 269-278 (2013)

Chen, J.S., Gursoy, D.: An investigation of tourists' destination loyalty and preferences. Int. J. Contemp. Hosp. Manag. 13(2), 79-85 (2001)

ChiCGQ, P.L., ChiappaG, D.: Examining destination personality: its antecedents and outcomes. J. Destin. Mark. Manag. 9, 149-159 (2018)

ChowASY, M.A.T.H., Wong, G.K.L., et al.: The impacts of place attachment on environmentally responsible behavioral intention and satisfaction of Chinese nature-based tourists. Sustainability 11(20), 5585 (2019)

Cohen, E.: A phenomenology of tourist experiences. Sociology 13(2), 179-201 (1979)

Csikszentmihalyi, M.: Beyond Boredom and Anxiety: the Experience of Play in Work and Games. JosseyBass, San Francisco (1975)

DwyerL, ChenN., Lee, J.: The role of place attachment in tourism research. J. Travel Tour. Mark. 36(5), 645-652 (2019)

EkinciY, S.-T., Baloglu, S.: Host image and destination personality. Tour. Anal. 12(5-6), 433-446 (2007)

Fitzgerald, L.A., Eijnatten, F.M.V.: Chaos speak: a glossary of chaordic terms and phrases. J. Organ. Chang. Manag. 15(4), 412-423 (2002)

Gohary, A., Pourazizi, L., Madani, F., et al.: Examining Iranian tourists' memorable experiences on destination satisfaction and behavioral intentions. Curr. Issue Tour. 23(2), 131-136 (2020)

Hair, J.F., Hult, G.T., Ringle, C.M., Sarstedt, M.: A Primer on Partial Least Squares Structural Equation Modeling. Sage Publication, Los Angeles (2017)

HallmannK, Z.A., Müller, S.: Perceived destination image: an image model for a winter sports destination and its effect on intention to revisit. J. Travel Res. 54(1), 94-106 (2015)

Hammitt, W.E., Backlund, E.A., Bixler, R.D.: Place bonding for recreation places: conceptual and empirical development. Leis. Stud. 25(1), 17-41 (2006)

Hidalgo, M.C., Hernández, B.: Place attachment: conceptual and empirical questions. J. Environ. Psychol. 21(3), 273-281 (2001)

Hosany, S., Prayag, G., Der VeenR, V., et al.: Mediating effects of place attachment and satisfaction on the relationship between tourists' emotions and intention to recommend. J. Travel Res. 56(8), 1079-1093 (2017)

Hosany, S., Witham, M.: Dimensions of cruisers' experiences, satisfaction, and intention to recommend. J. Travel Res. 49(3), 351-364 (2010)

Hsu, F.C., Scott, N.: Food experience, place attachment, destination image and the role of food-related personality traits. J. Hosp. Tour. Manag. 44, 79-87 (2020)

Huang, S., Weiler, B., Assaker, G.: Effects of interpretive guiding outcomes on tourist satisfaction and behavioral intention. J. Travel Res. 54(3), 344-358 (2015)

HuangYF, Z.Y., Quan, H.: The relationship among food perceived value, memorable tourism experiences and behaviour intention: the case of the Macao food festival. Int. J. Tour. Sci. 19(4), 258-268 (2019)

Hudson, S., Brent Ritchie, J.R.: Branding a memorable destination experience. The case of "Brand Canada." Int. J. Tour. Res. 11(2), 217-228 (2009) 
HuiTK, W.D., Ho, A.: Tourists' satisfaction, recommendation and revisiting Singapore. Tour. Manag. 28(4), 965-975 (2007)

Hultman, M., Skarmeas, D., Oghazi, P., et al.: Achieving tourist loyalty through destination personality, satisfaction, and identification. J. Bus. Res. 68(11), 2227-2231 (2015)

Kent, R.A., Argouslidis, P.C.: Shaping business decisions using fuzzy-set analysis: service elimination decisions. J. Mark. Manag. 21(5-6), 641-658 (2005)

Kim, H., Stepchenkova, S.: Understanding destination personality through visitors' experience: a crosscultural perspective. J. Dest. Mark. Manag. 6(4), 416-425 (2017)

Kim, J.H.: The antecedents of memorable tourism experiences: the development of a scale to measure the destination attributes associated with memorable experiences. Tour. Manag. 44, 34-45 (2014)

Kim, J.H.: The impact of memorable tourism experiences on loyalty behaviors: the mediating effects of destination image and satisfaction. J. Travel Res. 57(7), 856-870 (2018)

Kim, J.H., Brent Ritchie, J.R.: Cross-cultural validation of a memorable tourism experience scale (MTES). J. Travel Res. 53(3), 323-335 (2014)

Kim, J.H., Brent Ritchie, J.R., Mac Cormick, B.: Development of a scale to measure memorable tourism experiences. J. Travel Res. 51(1), 12-25 (2012)

Kim, J.H., Brent Ritchie, J.R., Tung, V.W.S.: The effect of memorable experience on behavioral intentions in tourism: a structural equation modeling approach. Tour. Anal. 15(6), 637-648 (2010)

Kim, K., Hallab, Z., Kim, J.N.: The moderating effect of travel experience in a destination on the relationship between the destination image and the intention to revisit. J. Hosp. Market. Manag. 21(5), 486-505 (2012)

Kock, N.: Common method bias in PLS-SEM: a full collinearity assessment approach. Int. J. E-Collab. 11(4), 1-10 (2015)

Krejcie, R.V., Morgan, D.W.: Determining sample size for research activities. Educ. Psychol. Meas. 30(3), 607-610 (1970)

Kronlund, A., Whittlesea, B.W.A., Yoon, C.: Consumer memory, fluency, and familiarity. In: Haugtvedt, C.P., Herr, P.M., Kardes, F.R. (eds.) Handbook of Consumer Psychology, pp. 1-75. Lawrence Erlbaum Associates, Mahwah (2008)

Larsen, S., Jenssen, D.: The school trip: travelling with, not to or from. Scand. J. Hosp. Tour. 4(1), 43-57 (2004)

Lee, J., Kyle, G., Scott, D.: The mediating effect of place attachment on the relationship between festival satisfaction and loyalty to the festival hosting destination. J. Travel Res. 51(6), 754-767 (2012)

LeeY, D.J., Howard, D.: The complex and dynamic nature of leisure experience. J. Leis. Res. 26(3), 195-211 (1994)

Lo, J.C., Kang, W.L., Hsu, C.H., et al.: Evaluation of place attachment, satisfaction, and responsible environmental behaviors of visitors to a constructed wetland on campus. J. Environ. Educ. Res. 15(1), 141-165 (2019)

Longest, K.C., Vaisey, S.: Fuzzy: a program for performing qualitative comparative analyses (QCA) in Stata. Stata J. 8(1), 79-104 (2008)

Loureiro, S.M.C.: The role of the rural tourism experience economy in place attachment and behavioral intentions. Int. J. Hosp. Manag. 40, 1-9 (2014)

$\mathrm{Mu}, \mathrm{I} .:$ The relationships between positive emotions, place attachment, and place satisfaction in casino hotels. Int. J. Hosp. Tour. Adm. 19(2), 167-186 (2018)

$\mathrm{Mu}, \mathrm{I}$., Wan, P.Y.K.: Relationships between tourism experiences and place attachment in the context of casino resorts. J. Qual. Assur. Hosp. Tour. 19(1), 45-65 (2018)

MacCannell, D.: Staged authenticity: arrangements of social space in tourist settings. Am. J. Sociol. 79(3), 589-603 (1973)

Martín-SantanaJD, B.-P., Nazzareno, P.A.: Antecedents and consequences of destination image gap. Ann. Tour. Res. 62, 13-25 (2017)

McDonald, J.R.: Complexity science: an alternative world view for understanding sustainable tourism development. J. Sustain. Tour. 17(4), 455-471 (2009)

Morgan, N., Pritchard, A.: Meeting the destination branding challenge. In: Morgan, N., Pritchard, A., Pride, R. (eds.) Destination Branding: Creating the Unique Destination Proposition, pp. 59-78. Butterworth-Heinemann, London (2004)

Morgan, N., Pritchard, A., Piggott, R.: New Zealand, 100\% pure. The creation of a powerful niche destination brand. J. Brand Manag. 9(4), 335-354 (2002)

Murphy, L., Benckendorff, P., Moscardo, G.: Linking travel motivation, tourist self-image and destination brand personality. J. Travel Tour. Mark. 22(2), 45-59 (2007)

Nilson, T.H.: Chaos Marketing: How to Win in a Turbulent World. McGraw-Hill, London (1995) 
Oh, H., Fiore, A.M., Jeong, M.: Measuring experience economy concepts: tourism applications. J. Travel Res. 46(2), 119-132 (2007)

Oliver, R.L.: Whence consumer loyalty? J. Mark. 63, 33-44 (1999)

Oppermann, M.: Tourism destination loyalty. J. Travel Res. 39(1), 78-84 (2000)

Ordanini, A., Parasuraman, A., Rubera, G.: When the recipe is more important than the ingredients: a qualitative comparative analysis (QCA) of service innovation configurations. J. Serv. Res. 17(2), 134-149 (2014)

Ozdemir, B., Aksu, A., Ehtiyar, R., et al.: Relationships among tourist profile, satisfaction and destination loyalty: examining empirical evidences in Antalya region of Turkey. J. Hosp. Market. Manag. 21(5), 506-540 (2012)

Pappas, N.: Risks and marketing in online transactions: a qualitative comparative analysis. Curr. Issue Tour. 20(8), 852-868 (2017)

Pappas, N.: The complexity of purchasing intentions in peer-to-peer accommodation. Int. J. Contemp. Hosp. Manag. 29(9), 2302-2321 (2017)

Pappas, N., Papatheodorou, A.: Tourism and the refugee crisis in Greece: perceptions and decision-making of accommodation providers. Tour. Manag. 63, 31-41 (2017)

Prayag, G., Hosany, S., Muskat, B., et al.: Understanding the relationships between tourists' emotional experiences, perceived overall image, satisfaction, and intention to recommend. J. Travel Res. 56(1), 41-54 (2017)

Prayag, G., Ryan, C.: Antecedents of tourists' loyalty to Mauritius: the role and influence of destination image, place attachment, personal involvement, and satisfaction. J. Travel Res. 51(3), 342-356 (2012)

Prayag, G., Suntikul, W., Agyeiwaah, E.: Domestic tourists to Elmina Castle, Ghana: motivation, tourism impacts, place attachment, and satisfaction. J. Sustain. Tour. 26(12), 2053-2070 (2018)

Ragin, C.C.: Fuzzy-Set Social Science. University of Chicago Press, Chicago (2000)

Ragin, C.C.: Redesigning Social Inquiry: Fuzzy Sets and Beyond. University of Chicago Press, Chicago (2008)

Ragin, C.C., Becker, H.S.: What is a Case? Exploring the Foundations of Social Inquiry. Cambridge University Press, Cambridge (1992)

Ramaseshan, B., Stein, A.: Connecting the dots between brand experience and brand loyalty: the mediating role of brand personality and brand relationships. J. Brand Manag. 21(7-8), 664-683 (2014)

Ramkissoon, H., Smith, L.D.G., Weiler, B.: Relationships between place attachment, place satisfaction and pro-environmental behaviour in an Australian national park. J. Sustain. Tour. 21(3), 434-457 (2013)

Russell, R., Faulkner, B.: Movers and shakers: chaos makers in tourism development. Tour. Manag. 20(4), 411-423 (1999)

Russell, R., Faulkner, B.: Entrepreneurship, chaos and the tourism area lifecycle. Ann. Tour. Res. 31(3), 556-579 (2004)

Seeger, M.W.: Chaos and crisis: propositions for a general theory of crisis communication. Public Relat. Rev. 28(4), 329-337 (2002)

Seljeseth, P.I., Korneliussen, T.: Experience-based brand personality as a source of value co-creation: the case of Lofoten. Scand. J. Hosp. Tour. 15(1), 48-61 (2015)

Sharma, P., Nayak, J.K.: Understanding memorable tourism experiences as the determinants of tourists' behaviour. Int. J. Tour. Res. 21(4), 504-518 (2019)

Skarmeas, D., Leonidou, C.N., Saridakis, C.: Examining the role of CSR skepticism using fuzzy-set qualitative comparative analysis. J. Bus. Res. 67(9), 1796-1805 (2014)

Souiden, N., Ladhari, R., Chiadmi, N.E.: Destination personality and destination image. J. Hosp. Tour. Manag. 32, 54-70 (2017)

Sthapit, E., Björk, P., Coudounaris, D.N.: Emotions elicited by local food consumption, memories, place attachment and behavioural intentions. Anatolia 28(3), 363-380 (2017)

Sultan, M.T., Sharmin, F., Xue, K.: Sharing tourism experience through social media: consumer's behavioral intention for destination choice. Int. J. Hum. Soc. Sci. 13(2), 129-133 (2019)

Tlili, H.T., Amara, D.: Towards emotional experience and place attachment as tourist satisfaction attributes. J. Bus. Econ. Policy 3(3), 108-119 (2016)

Tsai, C.T.: Memorable tourist experiences and place attachment when consuming local food. Int. J. Tour. Res. 18(6), 536-548 (2016)

Tsai, S.P.: Place attachment and tourism marketing: investigating international tourists in Singapore. Int. J. Tour. Res. 14(2), 139-152 (2012)

Tung, V.W.S., Ritchie, J.B.: Exploring the essence of memorable tourism experiences. Ann. Tour. Res. 38(4), 1367-1386 (2011)

Turkmen, S., Atay, L., Turkmen, E.: The examination of relationships between destination personality, satisfaction and behavioral intentions: case of Çanakkale. J. Yasar Univ. 13(49), 22-32 (2018) 
Urry, J.: The Tourist Gaze: Leisure and Travel in Contemporary Societies. Sage, London (1990)

Usakli, A., Baloglu, S.: Brand personality of tourist destinations: an application of self-congruity theory. Tour. Manag. 32(1), 114-127 (2011)

Vada, S., Prentice, C., Hsiao, A.: The influence of tourism experience and well-being on place attachment. J. Retail. Consum. Serv. 47, 322-330 (2019)

Veasna, S., Wu, W.Y., Huang, C.H.: The impact of destination source credibility on destination satisfaction: the mediating effects of destination attachment and destination image. Tour. Manag. 36, 511-526 (2013)

Vinyals-Mirabent, S., Kavaratzis, M., Fernández-Cavia, J.: The role of functional associations in building destination brand personality: when official websites do the talking. Tour. Manag. 75, 148-155 (2019)

Williams, D.R., Patterson, M.E., Roggenbuck, J.W.: Beyond the commodity metaphor: examining emotional and symbolic attachment to place. Leis. Sci. 14(1), 29-46 (1992)

Williams, P., Soutar, G.N.: Value, satisfaction and behavioral intentions in an adventure tourism context. Ann. Tour. Res. 36(3), 413-438 (2009)

Wirtz, D., Kruger, J., Scollon, C.N., et al.: What to do on spring break? the role of predicted, on-line, and remembered experience in future choice. Psychol. Sci. 14(5), 520-524 (2003)

Wong, J.W.C., Lai, I.K.W., Tao, Z.: Sharing memorable tourism experiences on mobile social media and how it influences further travel decisions. Curr. Issue Tour. 23(14), 1773-1787 (2020)

Woodside, A.G., Zhang, M.: Cultural diversity and marketing transactions: are market integration, large community size, and world religions necessary for fairness in ephemeral exchanges? Psychol. Mark. 30(3), 263-276 (2013)

World Tourism Organization (2020) Tourism highlights. https://www.unwto.org/news/unwto-highlightspotential-of-domestic-tourism-to-help-drive-economic-recovery-in-destinations-worldwide Accessed 1 Nov 2020

Wu, P.L., Yeh, S.S., Huan, T.C., et al.: Applying complexity theory to deepen service dominant logic: configural analysis of customer experience-and-outcome assessments of professional services for personal transformations. J. Bus. Res. 67(8), 1647-1670 (2014)

Yuksel, A., Yuksel, F., Bilim, Y.: Destination attachment: effects on customer satisfaction and cognitive, affective and conative loyalty. Tour. Manag. 31(2), 274-284 (2010)

Zahra, A., Ryan, C.: From chaos to cohesion-complexity in tourism structures: an analysis of New Zealand's regional tourism organizations. Tour. Manag. 28(3), 854-862 (2007)

Zhong, Y.Y., Busser, J., Baloglu, S.: A model of memorable tourism experience: the effects on satisfaction, affective commitment, and storytelling. Tour. Anal. 22(2), 201-217 (2017)

Publisher's Note Springer Nature remains neutral with regard to jurisdictional claims in published maps and institutional affiliations. 